\title{
ph

\section{El proyecto 3D-ICONS. El patrimonio de los iberos en la Biblioteca Digital Europea}

\author{
Alberto Sánchez Vizcaíno | Instituto Universitario de Investigación en Arqueología \\ Ibérica. Universidad de Jaén \\ Francisco Gómez Cabeza | Instituto Universitario de Investigación en Arqueología \\ Ibérica. Universidad de Jaén \\ Ana Martínez Carrillo | Instituto Universitario de Investigación en Arqueología Ibérica. \\ Universidad de Jaén \\ Arturo Ruiz Rodríguez | Instituto Universitario de Investigación en Arqueología Ibérica. \\ Universidad de Jaén \\ Francisca Hornos Mata | Museo provincial de Jaén. Consejería de Educación, Cultura \\ y Deporte
}

URL de la contribución <www.iaph.es/revistaph/index.php/revistaph/article/view/3456>

\section{RESUMEN}

La difusión del patrimonio histórico a través de la Biblioteca Digital Europea (Europeana) se ha convertido en una prioridad de la política cultural de la Unión Europea. La financiación de proyectos trata de asegurar el aporte a Europeana de información relacionada con el patrimonio arquitectónico y arqueológico en formato 2D y 3D. Uno de los proyectos que cumple con este objetivo es 3D-ICONS, formado por dieciséis socios de once países europeos, y en el que el Instituto Universitario de Investigación en Arqueología ibérica de Universidad de Jaén participa asegurando la presencia en Europeana de información 3D relativa a una de las culturas más importantes de la Edad del Hierro en la Península Ibérica: los iberos.

\section{Palabras clave}

Arqueología | Bibliotecas digitales | Europeana | Iberos | Patrimonio arqueológico | Patrimonio arquitectónico | 3D | 


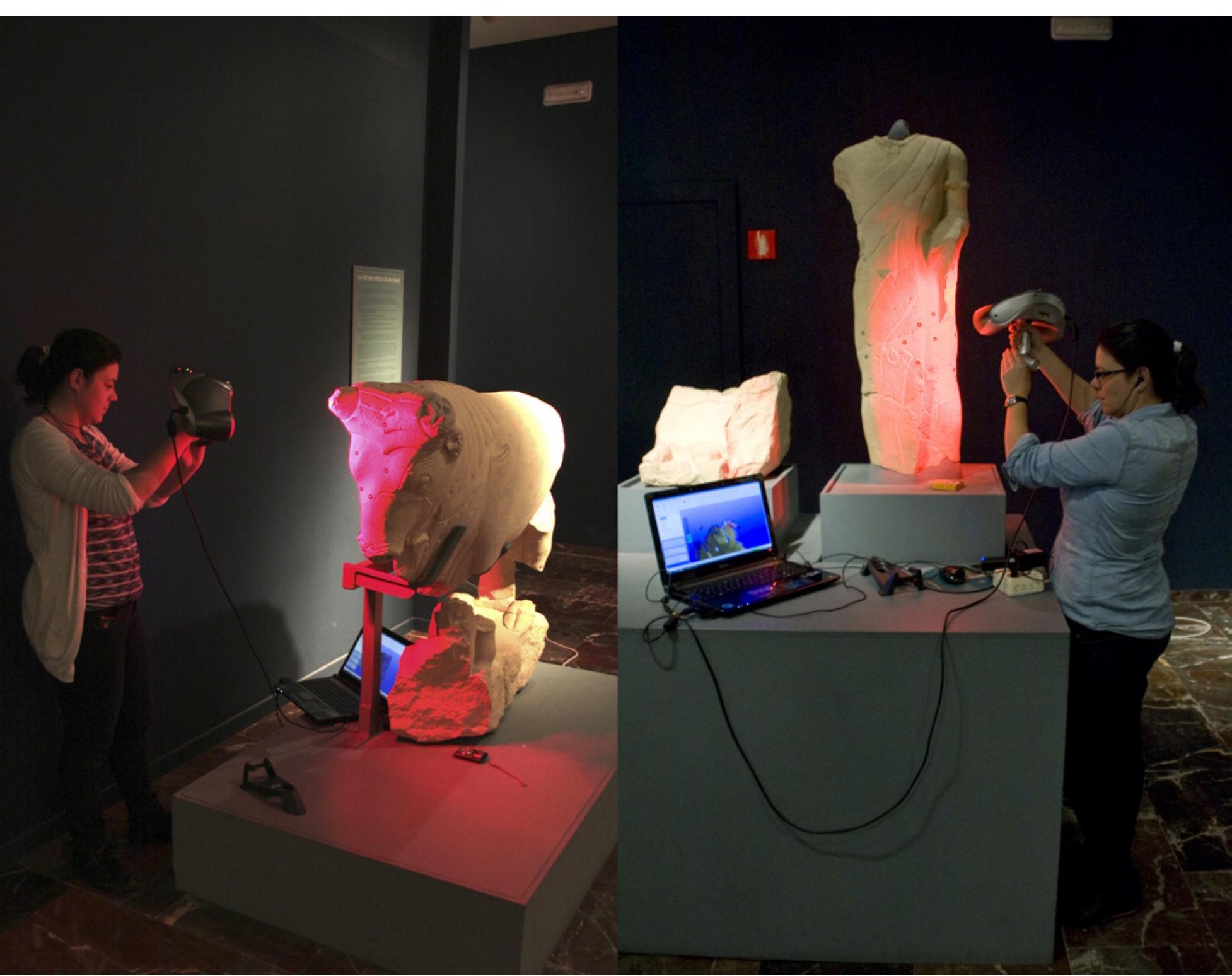

1. Toma de datos con escáner láser | foto Francisco Gómez 


\section{INTRODUCCIÓN}

El patrimonio cultural ha encontrado en los últimos años un nuevo cauce de divulgación y difusión a través de Internet. Dentro de esta dinámica surgió en 2005 el proyecto para la construcción de la biblioteca digital de la cultura europea conocida como Europeana y que comenzó a funcionar de manera efectiva en 2008 (www.europeana.eu/). El principal objetivo de esta biblioteca es hacer accesibles a los ciudadanos los recursos y colecciones digitales de archivos, museos, bibliotecas y archivos audiovisuales de Europa. La agregación de contenidos se está llevando a cabo de manera paulatina mediante la cooperación directa de instituciones europeas con el portal de Europeana y a través de la financiación de proyectos promovidos para dicho fin. En esta última línea de actuación se encuadran, entre otros, los proyectos europeos ATHENA (http://www.athenaeurope.org/), CARARE (Connecting ARchaeology and ARchitecture in Europeana) y 3D-ICONS (3D Digitisation of Icons of European Architectural and Archaeological Heritage). El primero de ellos se desarrolló en el marco del programa eContentplus y los dos siguientes han sido financiados por el programa ICT-PSP (Information and Communication Technologies-Policy Support Programme) en la modalidad de bibliotecas digitales.

El Instituto Universitario de Investigación en Arqueología Ibérica de la Universidad de Jaén (antiguo Centro Andaluz de Arqueología Ibérica, CAAI) es actualmente miembro de 3D-ICONS y su trabajo se dirige a la digitalización y aportación de contenidos relativos al patrimonio arqueológico de la cultura de los iberos en formato 3D. El Instituto ya contaba con experiencia en el manejo de datos y metadatos y en la transferencia de información a Europeana debido a su pertenencia al proyecto CARARE, un proyecto que se centró en la incorporación de contenidos ya digitalizados y principalmente en 2D a Europeana (HANSEN; FERNIE, 2010) (http://www.carare. eu/). Gracias al desarrollo de ambos proyectos, y a la transferencia de la información sobre los iberos a Europeana, se está haciendo realidad la posibilidad de ofrecer a la ciudadanía europea una visión actualizada sobre una de las culturas más importantes de la protohistoria andaluza, española y europea.

\section{EL PROYECTO 3D-ICONS}

\section{Definición y objetivos}

El proyecto 3D-ICONS está integrado por dieciséis miembros de once países europeos con experiencia significativa en la digitalización 3D del patrimonio arquitectónico y arqueológico. Su duración es de tres años (febrero 2012-febrero 2015) y la coordinación del proyecto la lleva a cabo el Centro 
Interdipartimentale di Servizi di Archeologia de la Università degli Studi di Napoli L’Orientale (Nápoles, Italia).

3D-ICONS tiene un doble objetivo, en primer lugar digitalizar tridimensionalmente un conjunto de edificios, monumentos y objetos de relevancia internacional y, en segundo, mejorar la difusión, protección y conservación del patrimonio histórico europeo mediante la incorporación de esos modelos con sus contenidos contextuales a Europeana, (D'ANDREA; NICCOLUCCI; FERNIE, 2012; D'ANDREA; NICCOLUCCI; BASSETT, 2012) (http://3diconsproject.eu/).

El proyecto además se ha construido sobre la identificación del conjunto de destinatarios interesados en la presencia de modelos 3D de algunos los principales conjuntos monumentales e históricos de Europa:

$>$ Estudiantes, turistas y público en general, todos ellos usuarios de Europeana, que quieren explorar y disfrutar de un patrimonio poco accesible o restringido por motivos de conservación.

$>$ Las instituciones culturales de nivel internacional y nacional encargadas de la gestión del patrimonio y que necesitan mecanismos eficaces para producir documentación en 3D de alta calidad y publicar los resultados tanto en Europeana como en sus propios sitios web.

$>$ La UNESCO y las instituciones culturales que deseen encontrar nuevas formas para aumentar la sostenibilidad del patrimonio europeo y mundial.

La primera fase del proyecto ha abarcado la recopilación e inventario de los monumentos disponibles y la información acerca de aspectos técnicos (formato, tamaño, derechos...). Los criterios de selección han tenido en cuenta el significado cultural del bien patrimonial, la facilidad de transformación en un formato de fácil manejo (3D-PDF, por ejemplo), coste del procedimiento y uso del recurso generado. Al final del proyecto, alrededor de sesenta bienes patrimoniales con gran significado o calificados como iconos culturales podrán contemplarse a través de Europeana, incorporando además cientos de modelos parciales 3D de edificios, detalles arquitectónicos y objetos, y todo ello acompañado de varios miles de imágenes de alta resolución.

El proyecto espera así obtener al final del periodo de ejecución unos 2500 modelos 3D para su publicación on-line. Entre los diferentes monumentos que podrán visualizarse parcial o totalmente en 3D pueden destacarse: la colina de Tara (Irlanda), las necrópolis etruscas (Italia), el Coliseo de Roma (Italia), los foros imperiales (Italia), la ciudad medieval de San Gimignano (Italia), la torre inclinada de Pisa (Italia), el palacio de Versalles (Francia) 
o el arco de Triunfo (Francia). A todos ellos habrá que añadir el patrimonio arqueológico de los iberos (D'ANDREA; NICCOLUCCI; FERNIE, 2012; D'ANDREA; NICCOLUCCI; BASSETT, 2012).

La digitalización del patrimonio arqueológico y arquitectónico requiere además de los oportunos permisos y autorizaciones de las autoridades encargadas de su gestión en cada país. Para los contenidos directamente digitalizados por el proyecto se han establecido convenios y acuerdos para su mejora, reutilización y agregación con los contenidos ya disponibles. Para su futuro uso por terceras partes, el proyecto está desarrollando un modelo de gestión de derechos de propiedad intelectual que será aceptable por la mayoría de los países de acuerdo con las diversas legislaciones existentes en Europa. El modelo, que prevé el libre acceso para uso personal, de manera similar a la establecida en Europeana usando aplicaciones como 3D-PDF y Venus 3D, permite además en caso de uso comercial la protección de los derechos de propiedad intelectual. La herramienta empleada se basará principalmente en tecnologías de código abierto, y la metodología y procesos de trabajo que el proyecto establecerá estarán disponibles para su uso por instituciones culturales y otras entidades propietarias del patrimonio cultural en 3D. La experiencia desarrollada por los miembros del proyecto les capacitará para ofrecer, individual o colectivamente, servicios de asesoramiento y consultoría, incluyendo en ello la puesta al día en aspectos tecnológicos (D'ANDREA; NICCOLUCCl; FERNIE, 2012).

\section{Los iberos en 3D-ICONS y Europeana}

El Instituto Universitario de Investigación en Arqueología Ibérica de la Universidad de Jaén participa en 3D-ICONS aportando la digitalización 3D de algunos de los sitios y materiales arqueológicos más representativos de la cultura de los iberos localizados en las provincias de Jaén, Granada y Málaga. En su selección se ha tenido en cuenta la relevancia del lugar o conjunto, el deseo de abarcar una secuencia temporal amplia (siglo VII al siglo I a. de C.), y la posibilidad de realizar, aunque no en todos los casos, una jerarquía de modelos desde el modelo 3D general del sitio hasta el objeto arqueológico contenido en él. En total se esperan poder obtener más de 500 modelos 3D procedentes de:

1. Conjunto escultórico de Cerrillo Blanco (Porcuna, Jaén). Las esculturas de Cerrillo Blanco constituyen el conjunto escultórico ibero más relevante de la Península Ibérica y su digitalización es uno de los objetivos prioritarios de este proyecto. Datadas en el siglo $\mathrm{V}$ a. de $\mathrm{C}$., las esculturas reflejan diversos aspectos de un linaje clientelar ibero agrupadas en diferentes grupos temáticos: antepasados, guerreros, luchas contra animales, escenas de caza, etc... (NEGUERUELA, 1990; OLMOS, 2002). La digitalización abarlas 


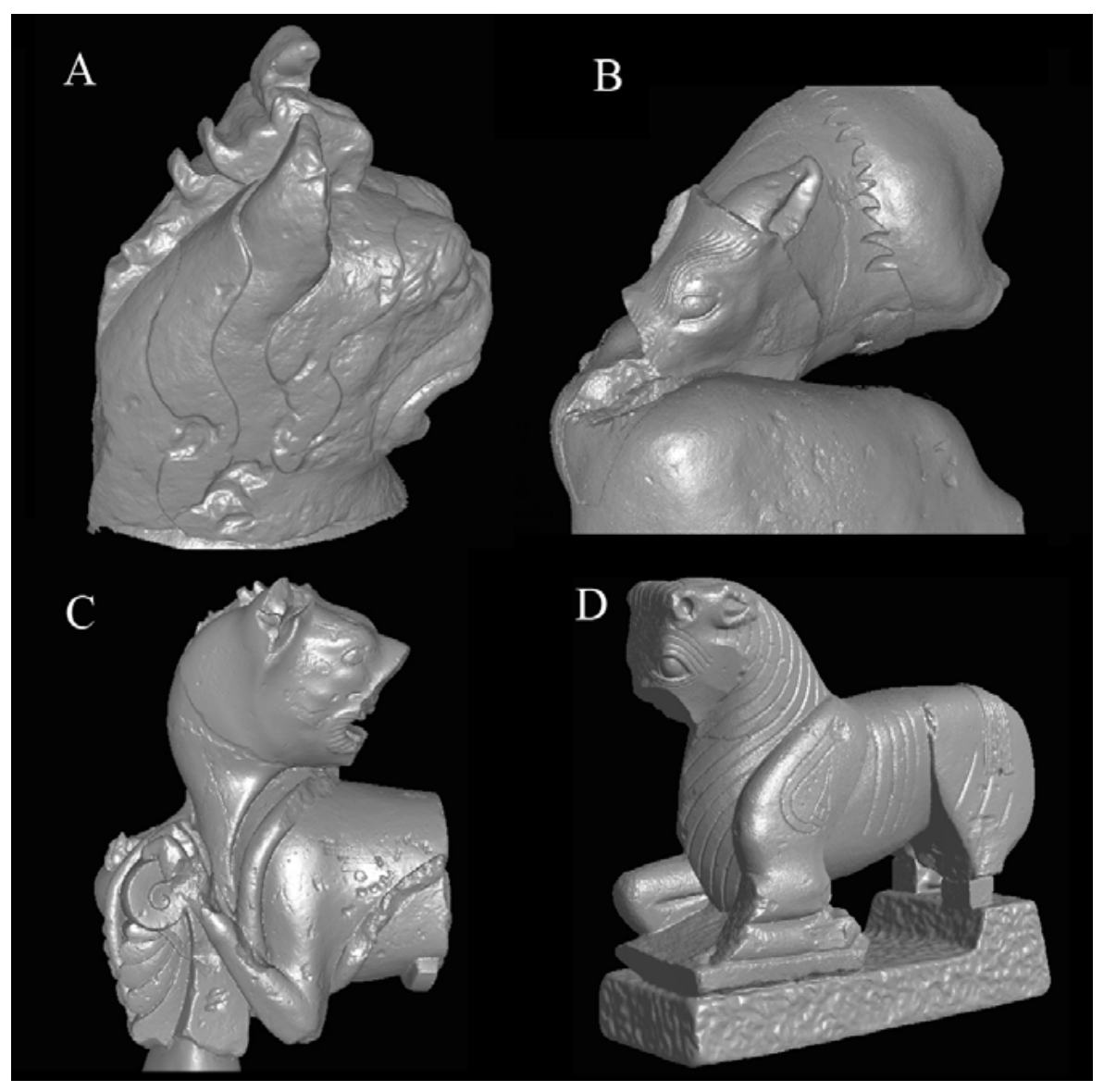

esculturas tanto en exhibición como aquellos fragmentos depositados en los fondos del Museo provincial de Jaén.

2. Conjunto escultórico de El Pajarillo (Huelma, Jaén). Descubierto oficialmente en 1993, aunque ya se conocían dos esculturas del grupo desde 1945, el conjunto está datado en el siglo IV a. de C. y se encuentra actualmente en exposición en el Museo provincial de Jaén. Las esculturas representan a un lobo, un guerrero, dos grifos, un muchacho joven y un carnívoro, componiendo una escena que expresa el momento en el que el aristócrata ibero adquiere la condición de héroe. El grupo escultórico se encontraba en la parte superior de una torre a la que se accedía por una escalera flanqueada por dos leones, estando todo el conjunto integrado en un gran lienzo de piedra de 80 metros de largo por 8 metros de ancho (MOLINOS; CHAPA; RUIZ, 1998) y configurando en su totalidad un santuario heroico.

3. Museo provincial de Jaén. Con independencia de los dos anteriores grupos escultóricos, el Museo provincial de Jaén expone un conjunto de materiales arqueológicos cerámicos y escultóricos iberos de alta relevancia que
2. Modelos 3D de diferentes esculturas del conjunto de Cerrillo Blanco (Porcuna, Jaén). A. Cabeza de grifo; B. Lobo devorando un cordero, C. Grifo con palmeta y serpiente; D. Toro 
lo convierten en uno de los museos de referencia para la cultura de los iberos. Entre los materiales que allí se encuentran en exposición pueden destacarse los pertenecientes a la necrópolis y poblado de Castellones de Ceal, la necrópolis del Ejido de las Eras de San Sebastián (La Guardia, Jaén), el relieve del domador de caballos (Mogón, Jaén), el relieve de Albanchez de Mágina (Jaén), exvotos de piedra de Torrebenzalá (Torredonjimeno) y La Bobadilla (Alcaudete), exvotos de bronce del santuario de los Altos del Sotillo (Castellar de Santisteban, Jaén) y del santuario de Collado de los Jardines (Santa Elena), esculturas de Cerro Alcalá (Torres, Jaén), la caja de Villargordo (Jaén) y materiales de Atalayuelas (Fuerte del Rey, Jaén) destacando el relieve de la danza bastetana (http://www.museosdeandalucia. es/culturaydeporte/museos/MJA/bibli).

4. El oppidum de Puente Tablas (Jaén). Es uno de los oppida más representativos de la cultura ibera en Jaén con un cronología que abarca desde el siglo VII hasta el siglo III a. de C. Las diversas campañas de excavación llevadas a cabo en él desde los años 80 por los profesores A. Ruiz y M. Molinos han puesto de manifiesto las áreas y sectores más relevantes de este asentamiento aportando nueva luz al conocimiento de la sociedad ibera (RUIZ; MOLINOS, 2007). Gracias a ello podrán obtenerse los modelos 3D de diversos tipos de casas, la manzana central, la muralla y bastiones, así como los más recientes hallazgos fruto de las campañas de excavación realizadas los tres últimos años: el palacio, el santuario, y la puerta del oppidum con la figura de la diosa orientada al equinoccio. Todos ellos se integrará en un modelo 3D general del asentamiento sobre el que localizar cada modelo parcial.

5. Murallas de los oppida de Ibros (Ibros, Jaén) y Cerro Miguelico (Torredelcampo, Jaén). Ambas murallas representan dos ejemplos de fortificación ibero-romana de tipo ciclópeo datadas en el siglo I a. de C.

6. La necrópolis de Piquía (Arjona, Jaén). Se trata de un área funeraria del siglo I a. de $\mathrm{C}$. con una variedad muy amplia de tipos de enterramiento (cámaras funerarias, cistas, columbario, etc.) que tienen en común la persistencia de un rito de incineración ibero, aun cuando ya han transcurrido casi dos siglos desde la conquista de Roma. De todos los hallazgos de la necrópolis destacan por su interés y singularidad la "caja de los guerreros", una urna en piedra con bajorrelieves de luchas entre guerreros y el ajuar de una cámara principesca con un excepcional bronce que forma parte de un carro y un conjunto de cráteras griegas de fines del siglo $\mathrm{V}$ a de $\mathrm{C}$. amortizadas en el ritual de enterramiento (OLMOS; RUEDA; RUIZ, 2012). Esta necrópolis igualmente ha aportado gran cantidad de materiales arqueológicos que ofrecen grandes posibilidades de análisis, mas de cien recipientes cerámicos de tradición ibérica con una amplia gama de decoraciones, elementos de vidrio, cerámicas importadas (cerámica campaniense, ánforas dressell, cerámica ática...). 


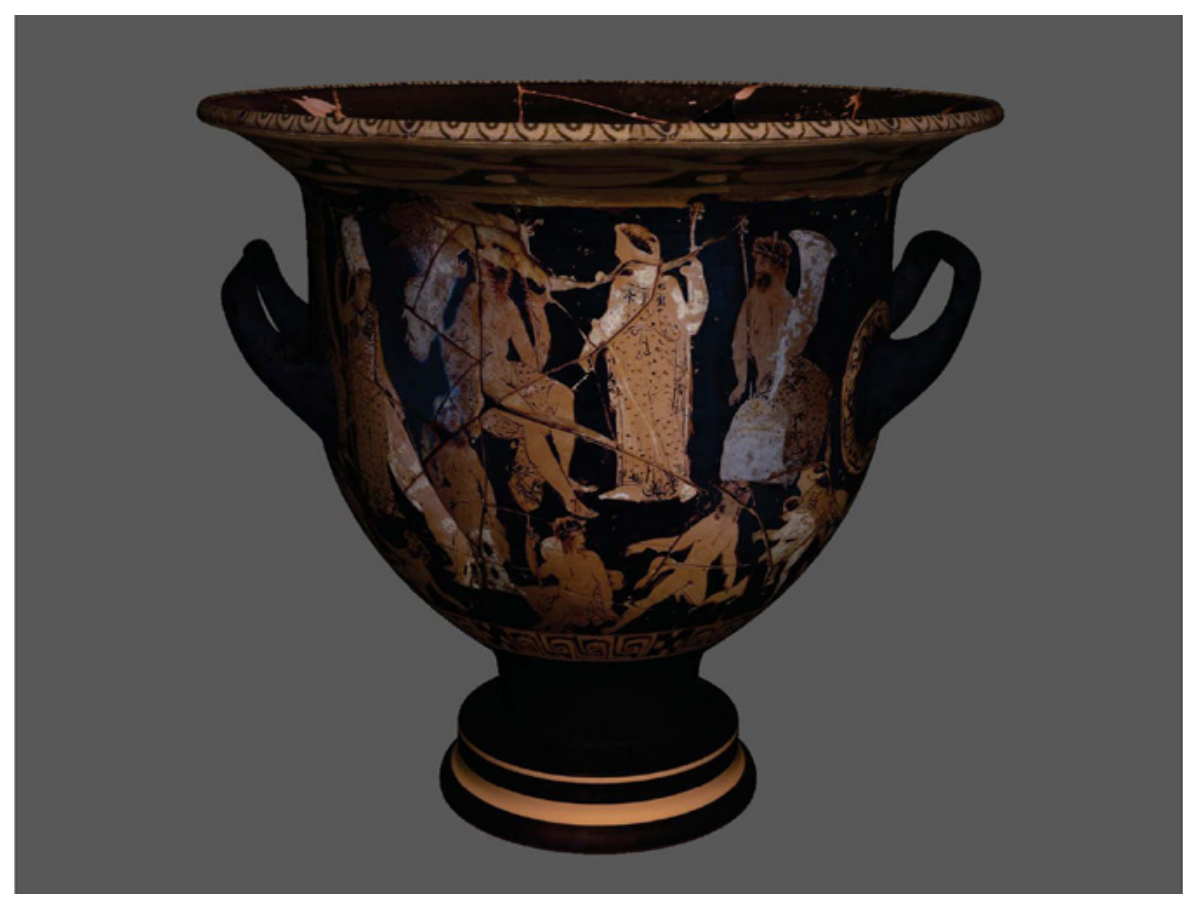

7. La necrópolis de Tutugi (Galera, Granada). Descubierta en 1916, es una necrópolis fundamental en la cultura ibérica que cuenta con 140 túmulos y sepulturas. Datada entre los siglos V y III a. de C., ha sido sometida desde el año 2000 a diversas campañas de excavación y puesta en valor que han aportado, a pesar de los saqueos a los que fue sometida, nuevos materiales: cerámicas, pasta vítrea, esculturas decoradas, urnas funerarias y revocos decorados (RODRÍGUEZ, 2010). A ellos hay que sumar los materiales depositados en el Museo de Galera (RODRÍGUEZ; GUILLEN, 2007). Gracias es estos trabajos se han obtenido modelos 3D de varios tumbas así como de recipientes cerámicos y otros tipos de materiales.

8. La necrópolis de La Noria (Fuente de Piedra, Málaga). Necrópolis orientalizante tumular de incineración con una datación que abarca desde la segunda mitad del siglo VI a. de C hasta inicios del V a. de C. Las investigaciones han puesto de manifiesto 8 túmulos excavados en la roca con foso perimetral y un total de 30 tumbas excavadas con un ajuar compuesto por cerámica decorada y sin decorar, pasta vítrea y otros materiales: cuencos, platos, kalathos, ánforas, aryballos, cuentas de collar de pasta vítrea Su importancia es fundamental para entender los procesos de iberización del territorio en el que se asienta. De ella se han obtenido los modelos 3D de la necrópolis, de cada tumba y de los ajuares.

9. La cámara de Toya (Peal de Becerro, Jaén). Una de las cámaras funerarias más relevantes de la cultura de los iberos, pertenece a la necrópolis
3. Modelo 3D de la cratera de Heracles de la necrópolis de Piquía (Arjona, Jaén) | foto Ana Martínez 
ibérica situada en el cerro de la Horca frente al castillo de Toya y está datada en el siglo IV a. de C (RUIZ; MOLINOS, 2010). El conjunto, descubierto en 1908, es conocido especialmente por su cámara sepulcral construida con piedra caliza, formada por tres naves paralelas, separadas por tabiques de piedra. Se espera obtener el modelo 3D de su interior y completarlo con los materiales arqueológicos depositados en el Museo provincial de Jaén.

10. Hipogeo del cerrillo de la Compañía (Hornos de Peal, Jaén). Tumba de cámara rectangular excavada en la roca, datada en el siglo VI a. de C. y situada frente a la necrópolis de Toya. En la tumba se depositaron las cenizas de una pareja hombre-mujer que no deja lugar a dudas del papel que está cobrando el linaje en el seno de la nueva sociedad y el interés en hacer visible esta estructura de parentesco a través de la propia pareja. La investigación del hipogeo ha permitido avanzar en el análisis de lo que debió ser la primera invención del paisaje funerario de los príncipes iberos en un momento antiguo del siglo VI a. de C (MOLINOS; RUIZ, 2007). Tanto el modelo 3D general como el del ajuar formarán parte del repertorio final de modelos iberos.

11. El Santuario de la cueva de la Lobera (Castellar, Jaén). El santuario está construido en un abrigo rocoso y data de los siglos IV-III a. de C. Es una pieza fundamental para entender la evolución del sistema territorial del pago de Cástulo así como la transformación del culto con la romanización. Uno de sus principales atractivos son los varios miles de exvotos de bronce que se debieron depositar en el mismo y que hoy se encuentran diseminados en museos de ciudades como Castellar, Jaén, Madrid, Barcelona y SaintGermain-en-Laye (Francia) (NICOLINI; RÍSQUEZ; RUIZ, 2004; RUEDA, 2011). Con el proyecto 3D-ICONS se digitalizarán la cueva del santuario, los exvotos y otros materiales de interés depositados en el Museo de Castellar.

12. Cerro de las Albahacas. Ubicación de la batalla de Baecula. Los trabajos de investigación desarrollados por el Instituto Universitario de Investigación en Arqueología Ibérica desde el año 2006 han dado lugar al descubrimiento de la famosa batalla de Baecula acontecida durante la Segunda Guerra Púnica en el año 208 a. de C. en el cerro de la Albahacas (Santo Tomé) frente al oppidum de Los Turruñuelos (BELLÓN; GÓMEZ; RUIZ, 2012). El proyecto ha planeado obtener el modelo 3D general del cerro, los de varias estructuras semisubterráneas y de los recipientes cerámicos.

Este conjunto de modelos e imágenes se unirá a las dos colecciones de imágenes ya presentes en Europeana gracias al citado proyecto CARARE (MARTINEZ; GÓMEZ; SÁNCHEZ, 2012; MARTÍNEZ; GÓMEZ; RUIZ, 2012). La primera colección se denominó Colección de Imágenes para la Enseñanza y Difusión de la Cultura de los Iberos e incluía 240 imágenes en 2D tanto de asentamientos como de las estructuras y materiales arqueológi- 
cos documentados y excavados localizados en Andalucía, Murcia, comunidad de Valencia y Cataluña. La segunda colección que incorporó CARARE es la denominada colección CATA. Debe su nombre al proyecto de excelencia CATA (Cerámica a torno de Andalucía, HUM-850) financiado por la Junta de Andalucía entre los años 2006 y 2010. Este proyecto generó una colección de referencia on-line de cerámica a torno (http://cata.cica.es) en la que se presentan tanto imágenes en 2D como modelos en 3D y videos (1143 3DPDF, 1139 imágenes y 1130 videos) (MARTÍNEZ; RUIZ; MOZAS, 2010).

Puede además añadirse como otra fuente de suministro de imágenes y documentos sobre los iberos a Europeana el directorio y recolector de recursos digitales Hispania, dependiente del Ministerio de Educación, Cultura y Deporte, y en el que se recogen las colecciones digitales de archivos, bibliotecas y museos españoles (http://roai.mcu.es/) (http://hispana.mcu.es/).

\section{METODOLOGÍA. DIGITALIZACIÓN Y GENERACIÓN DE MODELOS}

La estrategia de digitalización se basa en tres fases: adquisición, obtención del modelo y conversión a un formato adecuado para su publicación en Europeana. La adquisición de los datos cuenta hoy en día con un amplio repertorio de soluciones tecnológicas como son los escáneres laser de diverso tipo (triangulación, tiempo de vuelo), la fotogrametría, o la topografía (REMONDINO, 2011). El uso de cada uno de ellos dependerá de las circunstancias concretas de la estructura u objeto a digitalizar. La obtención, procesado y acabado del modelo 3D se articula en general en torno al empleo de software como MeshLab, Agisoft, Blender, Geomagic, CityEngine y SketchUp. Finalmente el modelo 3D generado se convertirá en un formato 3D de fácil visualización en Europeana, no obstante, y debido a las limitaciones del formato PDF que el proyecto ha detectado en modelos 3D complejos, 3D-ICONS no descarta otras soluciones como WebGL o NEXUS, si bien se está a la espera de un mayor desarrollo de las mismas.

En el caso del conjunto de objetos y estructuras del patrimonio de los iberos la metodología de digitalización se ha dividido entre el uso del escáner láser 3D y la fotogrametría.

El escáner láser (modelo Z-Scanner 800) empleado es un tipo de escáner que genera el modelo a partir de la identificación de puntos de posicionamiento (ver tabla página siguiente). En todo momento el escáner debe ser capaz de ver al menos cuatro de esos puntos. Para obtener máxima resolución en el trabajo desarrollado se realizan diversas tomas (hasta 26 en objetos de mayor tamaño) incluyendo cada toma 12 puntos de posicionamiento.

El modelo se obtiene posteriormente empleando el programa VXelements 
y la edición se ha llevado a cabo con el programa Geomagic v.10.0 (http:// www.geomagic.com/es/) (véanse las figuras 1 y 4 ).

Se ha recurrido al uso de este tipo de escáner en circunstancias concretas como consecuencia de limitaciones relacionadas con las condiciones de luz, accesibilidad, complejidad morfológica, peso y tamaño de los objetos que afectan la efectividad de los modelos obtenidos a partir de fotografía. Este conjunto de problemas se ha puesto de manifiesto en las salas de las esculturas de Cerrillo Blanco y de El Pajarillo en el Museo provincial de Jaén. Igualmente, y de manera más puntual, en recipientes cerámicos de las necrópolis de Piquía y La Noria en los que las superficies brillantes producían efectos de luz indeseados que dificultan la obtención de modelos de calidad o multiplicaban el trabajo hasta su finalización. Los modelos obtenidos en ambos casos con el escáner láser Z-Scanner 800 eliminan los problemas comentados y aportan una alta calidad (figuras 2 y 3 ).

En el caso del trabajo fotogramétrico, las imágenes se obtienen empleando las cámaras fotográficas Canon EOS 40D, Nikon 40D y GoPro Hero3 y los objetivos SIGMA DC $18-200 \mathrm{~mm}$ y EOS APO MACRO $350 \mathrm{~mm}$. El tamaño diverso de los objetos a digitalizar ha conducido a utilizar diferentes soluciones en función de la altura necesaria para obtener las fotos, haciéndose así

Tabla de características del escáner láser Z-Scanner 800

\begin{tabular}{|l|l|}
\hline Frecuencia de muestreo & 25.000 medidas por segundo \\
\hline Laser & Clase II \\
\hline Precisión XY & 40 micras \\
\hline Resolución & $0,050 \mathrm{~mm}$ XYZ (XYZ 0,0019) \\
\hline ISO & $20 \mu \mathrm{m}+0,1 \mathrm{~L} / 1000$ \\
\hline Profundidad de campo & $30 \mathrm{~cm}$ \\
\hline Formatos de exportación & $\begin{array}{l}\text { DAE, .FBX, .MA, .OBJ, .PLY, .STL, .TXT, } \\
\text { WRL, .X3D, .X3DZ, .ZPR }\end{array}$ \\
\hline
\end{tabular}


inevitable el uso de trípodes de 2 metros y 7 metros, grúas hidráulicas y dispositivos no tripulados.

El número de fotografías necesarias para generar el modelo 3D varía en función del tamaño y complejidad del objeto. Los modelos de objetos pequeños se están generando con una media de 36 fotografías, mientras que los modelos de sitios complejos como cuevas o grandes zonas arqueológicas requieren más fotografías (figura 5). Así por ejemplo, para obtener el modelo de la manzana central del oppidum de Puente Tablas (Jaén) han sido necesarias 210 fotografías mientras que para generar el modelo de la excavación de estructuras semisubterráneas del Cerro de las Albahacas (área de la batalla de Baecula, Santo Tomé, Jaén) se han tomado un total de 1173 fotografías.

El software con el que se está trabajando para la generación de modelos desde fotografía es Autodesk 123D Catch y Agisoft PhotoScan Professional

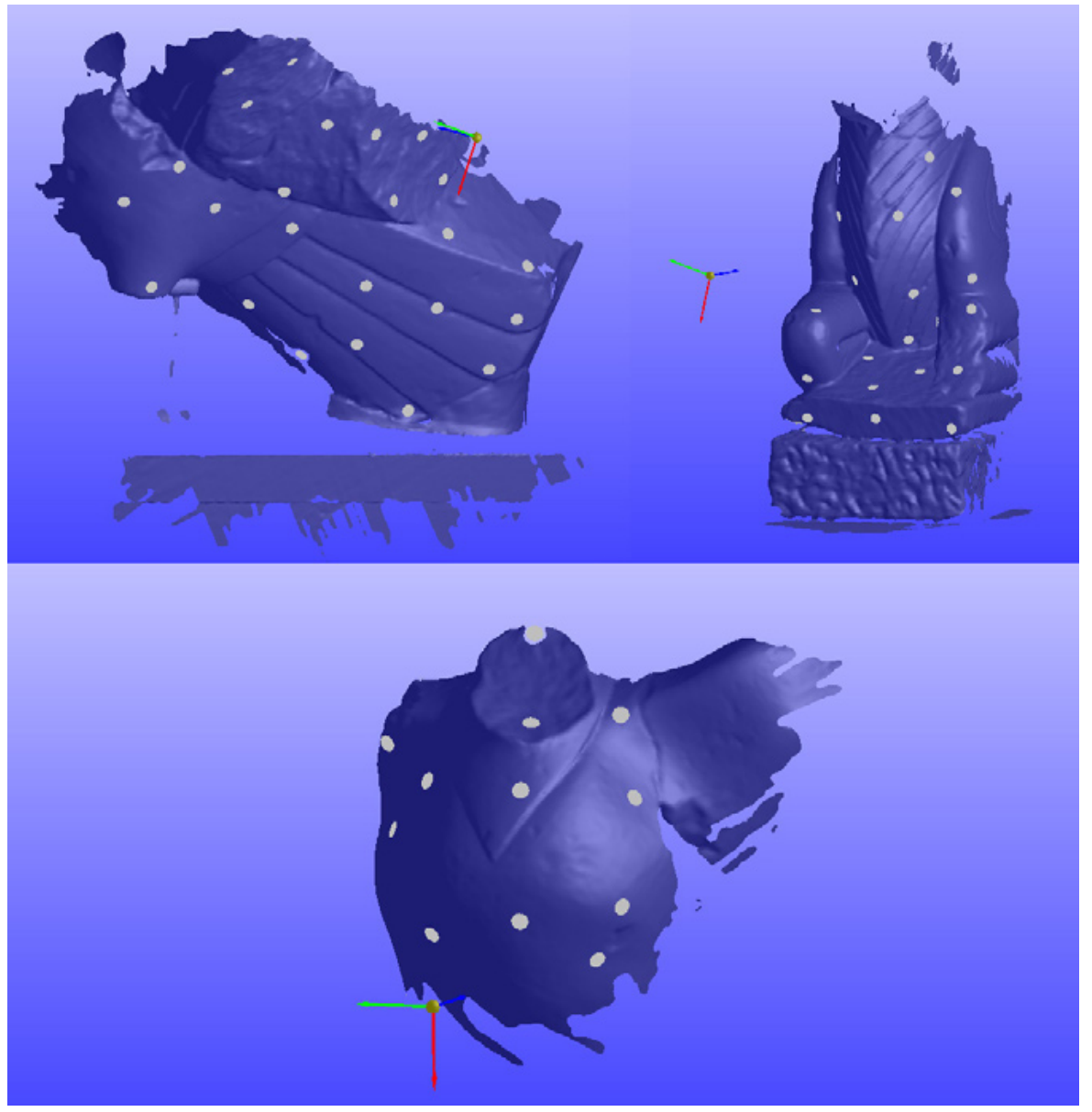

4. Puntos de posicionamiento para la creación del modelo con escáner láser | foto Ana Martínez

5. Posición de la cámara fotográfica para la toma de datos | foto Francisco Gómez

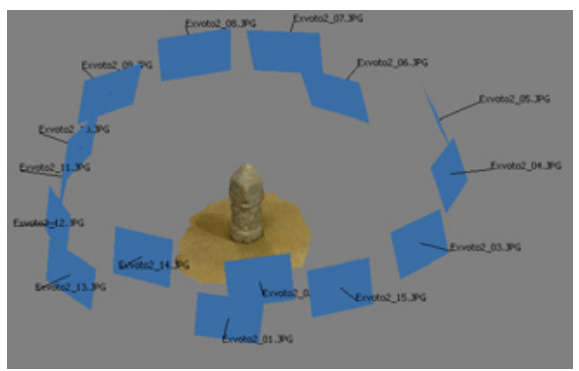



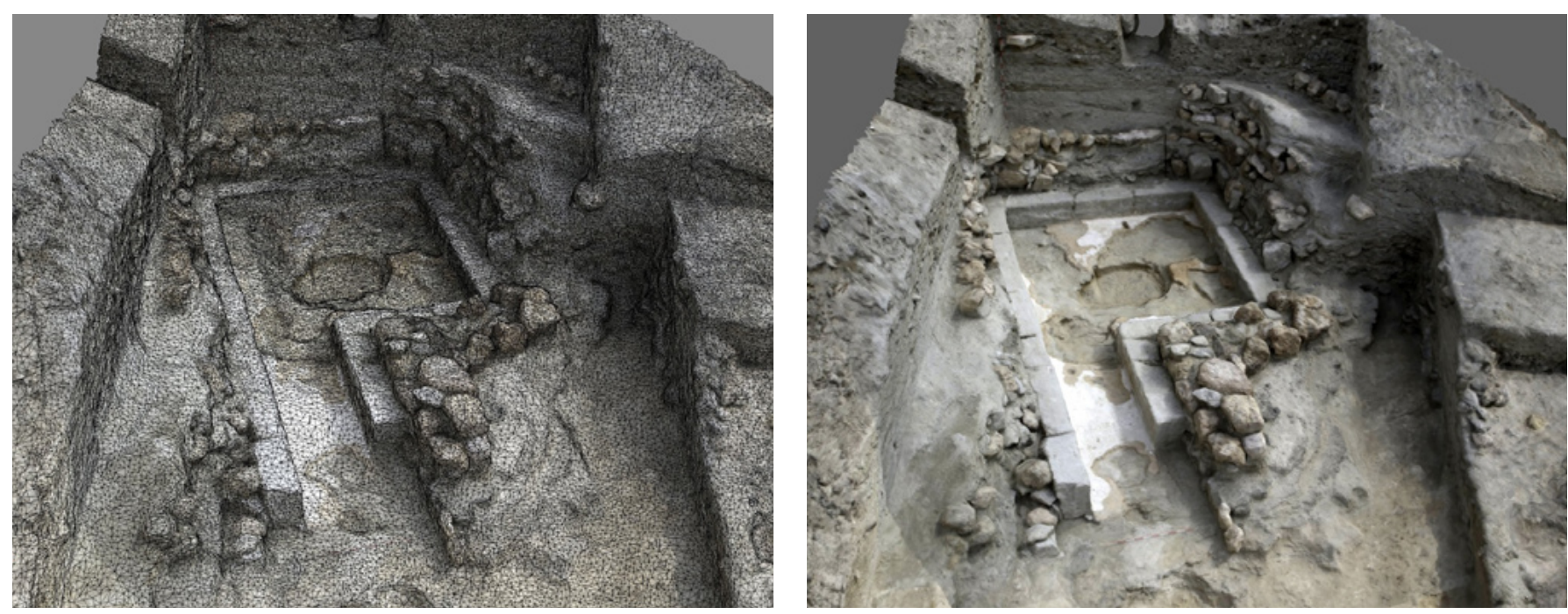

6. Malla y modelo $3 \mathrm{D}$ con la textura aplicada de la tumba 75 de la necrópolis de Tutugi (Galera,

Granada) | foto Francisco Gómez

Edition (http://www.agisoft.com/) aplicando una nube de puntos densa, mientras que el trabajo de edición y limpieza se lleva a cabo con los programas Meshlab (http://meshlab.sourceforge.net) y Blender (http://www.blender.org/) (véanse las figuras 6 y 7 ).

La fase final del trabajo consiste en la transformación de los modelos 3D a un formato que sea accesible a los usuarios de Europeana. Para permitir y facilitar la inclusión de contenidos en 3D, Europeana ya ha actualizado el EDM (European Data Model), los Elementos Semánticos (ESE, Europeana Semantic Elements), el corrector de contenido y el conjunto de herramientas de ingestión y la interfaz de usuario final.

Como primera opción se ha elegido la conversión a 3D-PDF como formato de fácil manejo mientras que las nuevas tecnologías como HTML5 y GML se desarrollan de manera definitiva (MASCI et ál., 2012; PLETINCKX, 2013). El 3D-PDF ha sido ampliamente aceptado como formato de presentación porque permite que los modelos 3D sean encapsulados y presentados a los usuarios con información contextual y con enlaces que permiten diferentes puntos de vista de los modelos. A ello hay que añadir dos características cruciales, es un software gratuito y está disponible en las principales plataformas (Windows, Mac OS, Linux). Este formato ha sido ya empleando por otros proyectos europeos como CARARE y Protage si bien no está exento de problemas. Algunos de ellos se reproducen en modelos de mayor tamaño o complejidad o cuando se quieren incorporar animaciones al modelo. En el caso de los modelos obtenidos sobre materiales iberos, el principal problema se produce en la conservación de las texturas en modelos complejos como son los de los conjuntos escultóricos de Cerrillo Blanco y El Pajarillo (figura 8). 


\section{METADATOS Y TRANSFERENCIA A EUROPEANA}

Uno de los problemas a los que el proyecto 3D-ICONS se enfrentó desde el principio era la necesidad de establecer un esquema común de metadatos para todos miembros del proyecto con objeto de transferir la información generada a Europeana.

Para la gestión de los metadatos, 3D-ICONS se ha basado en la experiencia acumulada en el proyecto CARARE al generar el esquema de metadatos CARARE (version 1.0) en formato XSD (XML Schema Definition) adecuado para Europeana. Su diseño se ha basado en esquemas estandarizados de metadatos ya existentes (MIDAS, LIDO) y es compatible con CIDOC CRM (RONZINO et ál., 2011; 2013). Posteriormente se estableció un proceso, codificado como XSLT (XML Schema Definition Language), mediante el cual los metadatos de 3D-ICONS fueron transformados al formato EDM (European Data Model) y normalizados para su incorporación al portal de Europeana (CHARLES, 2012). El proyecto 3D-ICONS ha generado una nueva versión del esquema CARARE haciéndolo más simple y teniendo en cuenta las peculiaridades de los modelos 3D y los avances en el modelo de metadatos de Europeana (D'ANDREA; FERNIE, 2013; D’ANDREA; NICCOLUCCI; FERNIE, 2013)

El esquema CARARE (versión.2.0) se centra en la descripción detallada de monumentos, en los acontecimientos o eventos en los que se ha visto involucrado, y en los recursos digitales que representan al monumento y aportan información sobre él. Su principal fortaleza reside por tanto en su capacidad para soportar una amplia gama de información descriptiva sobre monumentos, edificios, paisajes y sus representaciones tanto en 2D como en 3D. Las principales categorías del esquema son cuatro:

> Bien patrimonial: incorpora la descripción y la información espacio-temporal de los sitios arqueológicos, monumentos, edificios históricos, bienes industriales, paisajes arqueológicos, pecios, artefactos y ecofactos, así como libros, mapas, dibujos, fotografías, películas relacionados con el patrimonio arqueológico y arquitectónico.

> Recurso digital: incluye las imágenes, dibujos, planos, mapas, archivos, publicaciones y modelos 3D on-line asociados a los bienes patrimoniales.

> Información de la colección: describe la colección a la que pertenece el contenido suministrado.

> Actividad: se incluyen tanto los acontecimientos históricos que tuvieron lugar en el bien patrimonial (tales como construcción, alteración, demolición, batallas, etc), como las actividades arqueológicas (excavaciones, prospecciones, etc). 
7. Modelos 3D obtenidos mediante fotogrametría A. Palacio del oppidum de Puente Tablas (Jaén) B. Tumba 57 de la necrópolis de Tutugi (Galera, Granada); C. Exvotos de la campiña baja de Jaén. D. Relieve del domador de caballos (Mogón, Jaén) foto Francisco Gómez

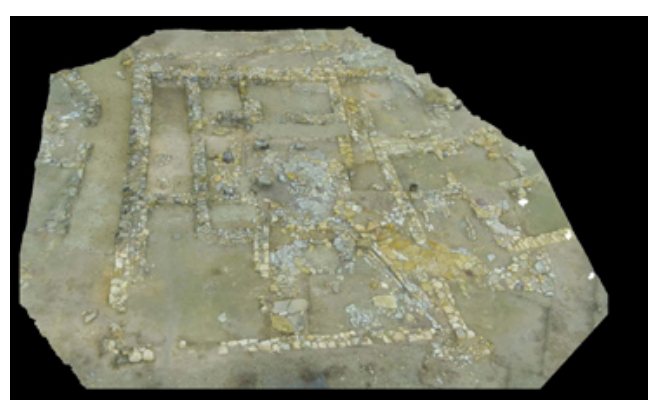

A

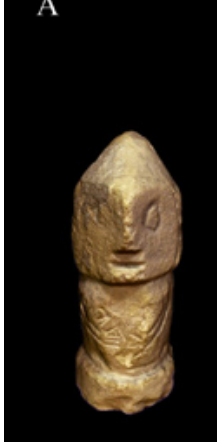

C

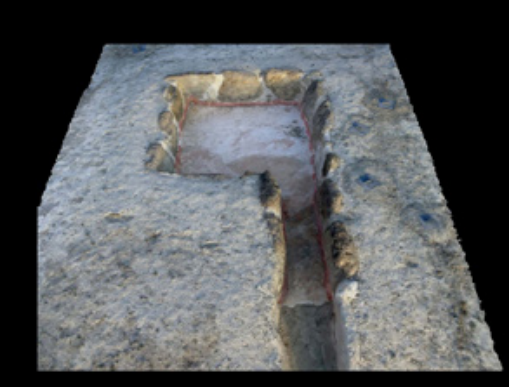

B

Una vez que todos los miembros del proyecto han adoptado el anterior esquema la información generada por su trabajo queda almacenada en un repositorio local desde donde los metadatos en formato XML se transfieren al entorno 3D-ICONS. La arquitectura técnica del proceso de transformación y agregación se ha completado con el desarrollo de dos herramientas (MINT2, Metadata Interoperability, y MORE2, MOnument REpository) que también tienen su origen en el proyecto CARARE. La primera es una herramienta de recopilación, mapeo semántico, asignación de valores y revisión de metadatos desarrollada por la Universidad Técnica Nacional de Atenas (Grecia) (http://mint.image.ece.ntua.gr). MORE2 es un repositorio diseñado por Centro de Investigación Athena (Grecia) donde los metadatos son transformados al formato EDM de Europeana y quedan disponibles para su publicación on-line (GAVRILIS; DALLAS; ANGELIS, 2013; PAPATHEODOROU; DALAS; ERTMANN-CHISTIANSEN, 2011).

\section{VALORACIÓN FINAL}

Uno de los retos a los que se enfrenta la gestión y difusión del patrimonio cultural es hacer accesible el patrimonio arqueológico y arquitectónico a una amplia audiencia y proporcionar al usuario una extensa gama de contenidos atractivos y reconocibles, ya sean a través de modelos 3D de objetos, monumentos o lugares más complejos o mediante modelos de realidad virtual. 


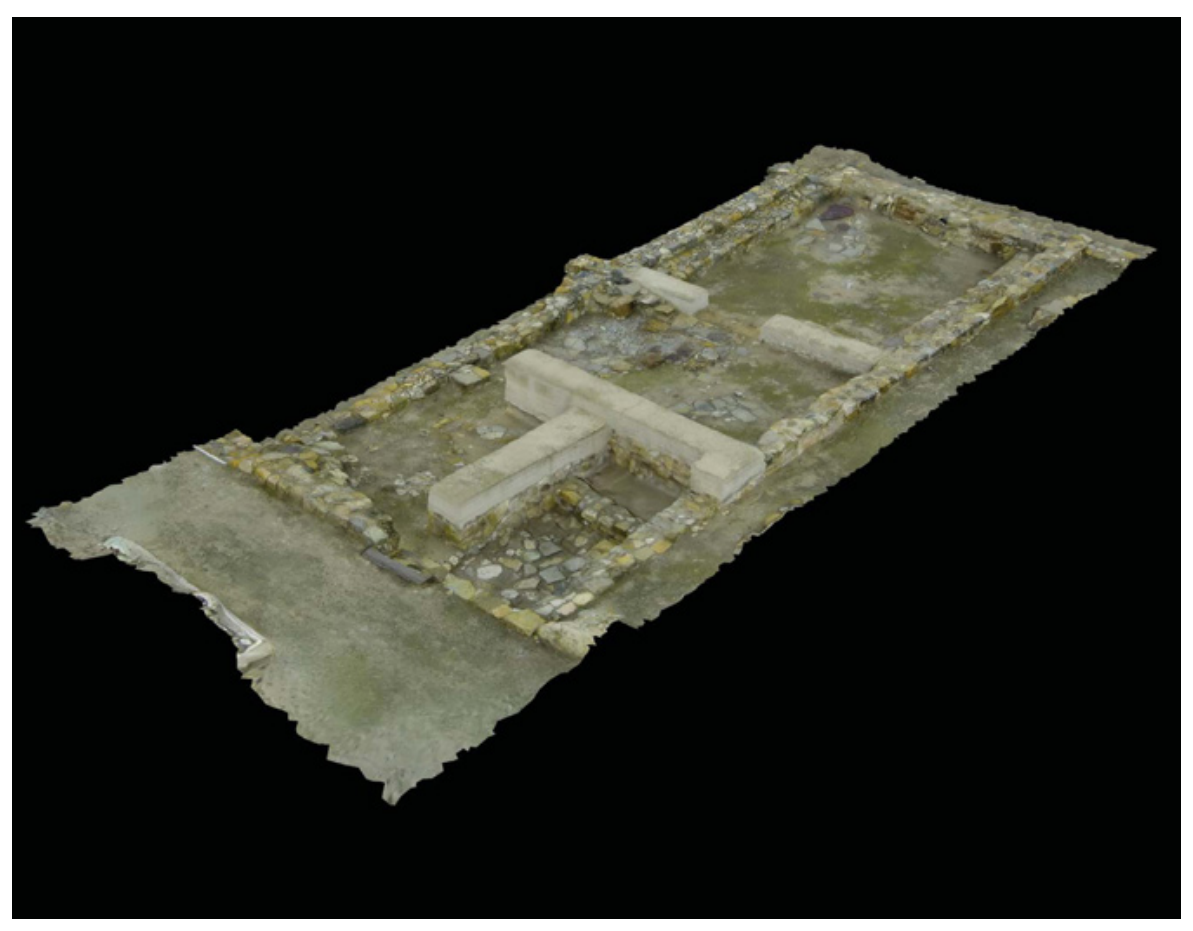

Cuando concluya en proyecto 3D-ICONS en febrero de 2015, y sus resultados se sumen a los ya obtenidos en el proyecto CARARE y por otras iniciativas similares, la Biblioteca Digital Europea contará con una importante colección de imágenes en diferentes formatos acompañadas de información contextual que acercará a los ciudadanos europeos a la cultura de los iberos, una de las culturas arqueológicas más interesantes de la Península Ibérica durante el primer milenio a. de C. En este sentido se estará respondiendo y dando solución parcial, que no definitiva, al reto anteriormente comentado ya que es evidente que todavía restan muchos objetos en museos y estructuras arqueológicas diversas pertenecientes a la cultura de los iberos por incorporar a Biblioteca Digital Europea. A ellas habrá que sumar además el rico patrimonio ibero aún desconocido y por descubrir que será necesario transferir en un futuro, que se espera no esté muy lejano, a Europeana.

\section{Agradecimientos}

Este trabajo ha sido financiado por el proyecto europeo 3D-ICONS: 3D Digitisation of Icons of European Architectural and Archaeological Heritage (contrato n. $\left.{ }^{\circ} 297194\right)$. Los autores agradecen la colaboración y el apoyo prestado por la Consejería de Cultura de la Junta de Andalucía, al Museo de Jaén, al Museo de Castellar, al Museo de Galera, al Instituto Universitario de Investigación en Arqueología Ibérica de la Universidad de Jaén, al proyecto europeo CARARE, a Carmen Rueda Galán y a Oliva Rodríguez Ariza.
8. Modelo 3D convertido a formato pdf de la casa 5 del oppidum de Puente Tablas (Jaén) | foto Francisco Gómez 


\section{BIBLIOGRAFÍA}

- BELLÓN, J. P.; GÓMEZ, F.; RUIZ, A. et ál. (2012) Un escenario bélico de la Segunda Guerra Púnica: Baecula". En REMEDIOS, S.; PRADOS, F.; BERMEJO, J. (eds.) Aníbal de Cartago. Historia y Mito. Madrid: Ediciones Polifemo, 2012, pp. 345-379

- D'ANDREA, A.; FERNIE K. (2013) CARARE 2.0: a metadata schema for 3D Cultural Objects. Digital Heritage 2013, International Congress, IEEE Proceedings, vol. 2, 2013, pp. 137-143

- D'ANDREA, A.; NICCOLUCCI, F.; FERNIE K. (2013) 3D ICONS metadata schema for 3D objects. Newsletter di Archeologia CISA, vol. 4, 2013, pp. 159-181

- D'ANDREA, A.; NICCOLUCCI, F.; FERNIE K. (2012) 3D-ICONS: European project providing 3D models and related digital content to Europeana. En CAPPELLINI, V. (ed.) Electronic Imaging \& the Visual Arts. Florencia: Firenze University Press, 2012, pp. 51-56

- D'ANDREA, A.; NICCOLUCCI, F.; BASSETT S. et ál. (2012) 3D-ICONS: World Heritage Sites for Europeana: Making Complex 3D Models Available to Everyone. Virtual Systems in the Information Society. Proceedings of 18th International Conference on Virtual Systems and Multimedia. Milán: Institute of Electrical and Electronics Engineers, Inc., 2012, pp. 517-520

- GAVRILIS, D.; DALLAS, C.; ANGELIS, S. (2013) A Curation-Oriented Thematic Aggregator. Lecture Notes in Computer Science, vol. 8092, 2013, pp. 132-137

- HANSEN, H. J.; FERNIE, K. (2010) CARARE: Connecting Archaeology and Architecture to Europeana. En IOANNIDES, M.; FELLNER, D.; GEORGOPOULOS, A. et ál. (eds.) Digital Heritage: Third International Conference, EuroMed 2010. Lemessos, Cyprus, Lecture Notes in Computer Science, vol. 6436, 2010, pp. 450-462

- MARTínEZ, A. L.; GÓMEZ, F.; RUIZ, A. et ál. (2012) El patrimonio arqueológico ibérico en la Biblioteca Digital Europea. En Actas I Congreso Internacional de Patrimonio Cultural y Natural como motor de desarrollo: Investigación e Innovación. Jaen: Universidad Internacional de Andalucía, 2012, pp. 2270-2283

- MARTÍNEZ, A. L.; GÓMEZ, F.; SÁNCHEZ. A. (2012) Integración de contenidos 3D de la cultura ibérica en Europeana. Virtual Archaeology Review, vol. 3, n. ${ }^{\circ}$ 7, 2012, pp. 27-30

- MARTínEZ, A. L.; RUIZ, A; MOZAS, F. et ál. (2010) An interactive system for storage, analysis, query and visualization of archaeological pottery. En FRISCHER, B., CRAWFORD, J. W.; KOLLER D. (eds.). Making History Interactive. ComputerApplications and Quantitative Methods in Archaeology (CAA). Williamsburg: Archaeopress, 2010 <http://www.caa2009.org/articles/Carrillo Contribution240. pdf> [Consulta: 08/10/2014]
- MASCI, M. E.; DE SANTIS, A.; FERNIE, K. et ál. (2012) 3D in the CARARE Project. Providing Europeana with 3D Content for the Archaeological and Architectural Heritage: the Pompeii Case Study. En Virtual Systems in the Information Society. Proceedings of 18th International Conference on Virtual Systems and Multimedia. Milán: Institute of Electrical and Electronics Engineers, Inc., 2012, pp. $227-234$

- MOLINOS, M.; CHAPA, T.; RUIZ, A. et ál. (1998) El Santuario Heroico de "El Pajarillo" Huelma (Jaén). Jaén: Universidad de Jaén, 1998

- MOLINOS, M.; RUIZ, A. (2007) El hipogeo ibero del Cerrillo de la Compañía de Hornos (Peal de Becerro, Jaén). Jaen: Junta de Andalucía; Universidad de Jaén, 2007

- NEGUERUELA, L. (1990) Los monumentos escultóricos ibéricos de Cerrillo Blanco de Porcuna (Jaén). Madrid: Ministerio de Cultura, 1990

- NICOLINI, G.; RísQUEZ, C.; RUIZ, A. et ál. (2004) El Santuario ibérico de Castellar. Jaén. Investigaciones Arqueológicas 1966-1991. Sevilla: Junta de Andalucía, 2004

- PAPATHEODOROU C.; DALLAS, C.; ERTMANNCHRISTIANSEN, C. et ál. (2011) New Architecture and Approach to Asset Representation for Europeana Aggregation: The CARARE Way. Metadata and Semantic Research. Communications in Computer and Information Science, vol. 240, 2011, p. 412-423

- PLETINCKX, D. (2013) Archaeology and Monuments in 3D in Europeana. EAC Occasional Paper, n. ${ }^{\circ} 7,2013$, pp. 171-179

- REMONDINO, F. (2011) Recording and 3D Modeling with Photogrammetry and 3D Scanning. Remote Sensing, vol. 3, 2011, pp. 1104-1138

- RODRíguEZ ARIZA, M. O. (2010) Tútugi, del sueño a la realidad. En Viejos Yacimientos, Nuevas Aportaciones. Madrid: Ministerio de Cultura, 2010, pp.13-52

- RODRÍGUEZ ARIZA, M. O.; GUILLÉN, J. (2007) Museo de Galera. Guía oficial. Granada: Diputación de Granada; Ayuntamiento de Galera, 2007

- RONZINO P.; AMICO N.; NICCOLUCCI F. (2011) Assessment and comparison of metadata schemas for architectural heritage. Proceedings of XXIIIrd International CIPA Symposium. Prague: Czech Technical University in Prague, Faculty of Civil Engineering and CIPA, <http:// cipa.icomos.org/fileadmin/template/doc/PRAGUE/127.pdf> [Consulta: 08/10/2014]

- RONZINO, P.; NICCOLUCCI, F.; D'ANDREA, A. (2013) Built Heritage metadata schemas and the integration of architectural datasets using CIDOC-CRM. Proceedings of the Conference Built Heritage 2013 Monitoring Conservation 


\section{SITIOS WEB}

Management. Milano: Politecnico di Milano, Centro per la Conservazione e Valorizzazione dei Beni Culturali, 2013, pp. 883-889, <http://www.bh2013.polimi.it/papers/bh2013_ paper_318.pdf> [Consulta: 08/10/2014]

- RUEDA, C. (2011) Territorio, culto e iconografía en los santuarios iberos del Alto Guadalquivir (ss. IV a.n.e.-I d.n.e). Caaiberica. Textos 3. Jaen: Universidad de Jaén, 2011

- RUIZ, A.; MOLINOS, M. (2007) Iberos en Jaén. CAAI Textos. Jaén: Instituto Universitario de Investigación en Arqueología Ibérica, 2007

- RUIZ, A.; MOLINOS, M. (2010) De la Cámara de Toya al Hipogeo de Hornos. En Viejos Yacimientos, Nuevas Aportaciones. Madrid: Ministerio de Cultura, 2010, pp. 5477

- OLMOS, R. (2002) Los grupos escultóricos del Cerrillo Blanco de Porcuna (Jaén). Un ensayo de lectura iconográfica convergente. Archivo Español de Arqueología, vol. 75, n. ${ }^{\circ}$ 185-186, 2002, pp.107-122

- Olmos, R.; RUEDA, C.; RUIZ, A. et ál. (2012) ¿Imágenes para un linaje: vida, muerte y memoria ritual en la Cámara principesca de Piquía (Arjona, Jaén)? En ANGIOLILLO, S.; GIUMAN, M.; PILO, C. (dir.) Dinamiche di stratificazione culturale nella periferia greca e romana. Roma: Bretschneider, 2012, pp. 89-104
- AGISOFT: http://www.agisoft.com/

- ATHENA: http://www.athenaeurope.org/

- BLENDER: http://www.blender.org/

- CARARE: http://www.carare.eu/

- CATA: http://cata.cica.es

- EUROPEANA : http://www.europeana.eu/

- EDM Case Study: CARARE and EDM: <http://pro. europeana.eu/web/guest/carare-edm>

- GEOMAGIC: http://www.geomagic.com/es/

- HISPANA: http://roai.mcu.es/; http://hispana.mcu.es/

- 3D-ICONS: http://3dicons-project.eu/

- MESLAB: http://meshlab.sourceforge.net/

- MINT: http://mint.image.ece.ntua.gr/

- MUSEO DE JAÉN: http://www.museosdeandalucia. culturaydeporte/museos/MJA/ 